\title{
Edelstein type fixed point theorems
}

\section{Erdal Karapınar}

\section{"Correspondence:}

erdalkarapinar@yahoo.com;

ekarapinar@atilim.edu.tr

Department of Mathematics, Atılım

University, İncek, Ankara 06836, Turkey

\begin{abstract}
In this manuscript, we investigate certain conditions that imply the existence of fixed points for almost contraction mappings defined on compact metric spaces.

Furthermore we introduce a criteria establishing the uniqueness of fixed points for the mentioned operators. As a result we obtain generalized results by unifying some recent related fixed point theorems on the topic.
\end{abstract}

\section{Introduction and Preliminaries}

In nonlinear functional analysis, fixed point theory is being investigated increasingly by reason of the fact that it has a wide range of applications in fields such as economics (see e.g. $[1,2]$ ), computer science (see e.g. [3-7]), and many others. One of the pioneering theorems in this direction is the Banach contraction mapping principle [8] which states that each contraction defined on a complete metric space $X$ has a unique fixed point. Banach's result is the origin and antecedents results by the fact that he not only proved the existence and uniqueness of a fixed point of a contraction, but also showed how to evaluate this point. After this celebrated result[8], a number of authors have observed various other types of contraction mappings and proved related fixed point theorems (see e.g. such as Kannan [9], Reich [10], Hardy and Rogers [11], Ćirić [12-14], Zamfirescu [15], Arshad et al. [16]). By following this trend Suzuki recently proved the following fixed point theorems:

Theorem 1 (Suzuki [17]) Let $(X, d)$ be a compact metric space and let $T$ be a mapping on $X$. Assume that $\frac{1}{2} d(x, T x)<d(x, y)$ implies $d(T x, T y)<d(x, y)$ for all $x, y \in X$. Then $T$ has a unique fixed point.

Theorem 2 (Suzuki [18]) Define a non-increasing function $\theta$ from $[0,1)$ onto $(1 / 2,1]$ by

$$
\theta(r)= \begin{cases}1 & \text { if } 0 \leq r \leq(\sqrt{5}-1) / 2, \\ (1-r) r^{-2} & \text { if }(\sqrt{5}-1) / 2 \leq r \leq \sqrt{2} / 2, \\ (1+r)^{-1} & \text { if } \sqrt{2} / 2 \leq r<1 .\end{cases}
$$

Then for a metric space $(X, d)$, the followings are equivalent:

1. $X$ is complete;

2. Every mapping $T$ on $X$ satisfying the following has a fixed point: There exists $r \in[0,1)$ such that $\theta(r) d(x, T x) \leq d(x, y)$ implies $d(T x, T y) \leq r d(x, y)$ for all $x, y \in X$.

(c) 2012 Karapınar; licensee Springer. This is an Open Access article distributed under the terms of the Creative Commons Attribution License (http://creativecommons.org/licenses/by/2.0), which permits unrestricted use, distribution, and reproduction in any medium, provided the original work is properly cited. 
In the literature Theorem 1 and Theorem 2 attracted considerable attention from many authors (see e.g. [19-23]). Notice that these theorems are inspired by Edelstein's Theorem [24]:

Theorem 3 Let $(X, d)$ be a compact metric space and let $T$ be a mapping on $X$. Assume $d(T x, T y)<d(x, y)$ for all $x, y \in X$ with $x \neq y$. Then $T$ has a unique fixed point.

Motivated by these developments in this area, in this manuscript, we combine wellknown results of Suzuki [17], Edelstein [24] and Berinde [25] to complement a multitude of related results from the literature. For the sake of completeness we include the results of Berinde as well:

Theorem 4 (See [25]) Let $(X, d)$ be a complete metric space and $T: X \rightarrow X$ be an almost contraction, that is, a mapping for which there exist a constant $k \in[0,1)$ and some $L \geq 0$ such that

$$
d(T x, T y) \leq k d(x, y)+L d(y, T x)
$$

for all $x, y \in X$. Then $\operatorname{Fix}(T)=\{x \in X: T x=x\} \neq \emptyset$.

Theorem 5 (See [25]) Let $(X, d)$ be a complete metric space and $T: X \rightarrow X$ be an almost contraction, that is, a mapping for which there exist a constant $k \in(0,1)$ and some $L \geq 0$ such that

$$
d(T x, T y) \leq k d(x, y)+L d(x, T x)
$$

for all $x, y \in X$. Then has a unique fixed point.

\section{Main Theorems}

We start this section by proving the following theorem:

Theorem 6 Let $T$ be a self mapping on a compact metric space $(X, d)$. Assume that

$$
\begin{aligned}
& \frac{1}{2} d(x, T x)<d(x, y) \\
& \quad \Rightarrow \quad d(T x, T y)<\frac{1}{2}[d(T x, x)+d(T y, y)]+L \min \{d(y, T x), d(x, T y), d(x, y)\}
\end{aligned}
$$

for all $x, y \in X$ with $x \neq y$ and $L>0$. Then, $T$ has a fixed point $z \in X$, that is, $T z=z$.

Proof Set $\theta=\inf \{d(x, T x): x \in X\}$ and choose a sequence $\left\{x_{n}\right\}$ in $X$ such that $\lim _{n \rightarrow \infty} d\left(x_{n}\right.$, $\left.T x_{n}\right)=\theta$. Regarding that $X$ is compact, without loss of generality, assume that $\left\{x_{n}\right\}$ and $\left\{T x_{n}\right\}$ converge to the points $z$ and $w$ in $X$, respectively. 
We claim that $\theta$ is equal to zero. To show this, assume to the contrary that $\theta>0$. Observe that we have

$$
\lim _{n \rightarrow \infty} d\left(x_{n}, w\right)=d(z, w)=\lim _{n \rightarrow \infty} d\left(x_{n}, T x_{n}\right)=\theta .
$$

We can choose $k \in \mathbb{N}$ in such a way that

$$
\frac{2}{3} \theta<d\left(x_{n}, w\right) \quad \text { and } \quad d\left(x_{n}, T x_{n}\right)<\frac{4}{3} \theta
$$

for each $n \geq k$. As a consequence, we have $\frac{1}{2} d\left(x_{n}, T x_{n}\right)<d\left(x_{n}, w\right)$ for each $n \geq k$. Due to (3), we get $d\left(T x_{n}, T w\right)<\frac{1}{2}\left[d\left(T x_{n}, x_{n}\right)+d(T w, w)\right]$ for each $n \geq k$. Accordingly, we obtain

$$
\begin{aligned}
& d(w, T w) \\
& \quad=\lim _{n \rightarrow \infty} d\left(T x_{n}, T w\right) \\
& \quad \leq \lim _{n \rightarrow \infty}\left(\frac{1}{2}\left[d\left(T x_{n}, x_{n}\right)+d(T w, w)\right]+L \min \left\{d\left(w, T x_{n}\right), d\left(x_{n}, T w\right), d\left(x_{n}, w\right)\right\}\right)
\end{aligned}
$$

which implies that

$$
d(w, T w) \leq d(w, z)=\theta
$$

By taking the definition of $\theta$ into account, we conclude that $d(w, T w)=\theta$. Notice that the inequality $\frac{1}{2} d(w, T w)<d(w, T w)$ always holds. By applying the condition (3) again, we find

$$
\begin{aligned}
d\left(T w, T^{2} w\right)< & \frac{1}{2}\left[d(T w, w)+d\left(T^{2} w, T w\right)\right] \\
& +L \min \left\{d(T w, T w), d\left(w, T^{2} w\right), d(w, T w)\right\}
\end{aligned}
$$

which is equivalent to the inequality $d\left(T w, T^{2} w\right)<d(T w, w)=\theta$. This contradicts with the definition of $\theta$. Hence, we conclude that $\theta=0$.

We next assert that $T$ has a fixed point. We use the method of Reductio ad absurdum to show this assertion. Suppose that $T$ has no fixed points. Since the inequality $0<\frac{1}{2} d\left(T x_{n}, x_{n}\right)<d\left(T x_{n}, x_{n}\right)$ holds for each $n$, we derive, for every $n \in \mathbb{N}$, that

$$
\begin{aligned}
d\left(T x_{n}, T^{2} x_{n}\right)< & \frac{1}{2}\left[d\left(T x_{n}, x_{n}\right)+d\left(T^{2} x_{n}, T x_{n}\right)\right] \\
& +L \min \left\{d\left(T x_{n}, T x_{n}\right), d\left(x_{n}, T^{2} x_{n}\right), d\left(x_{n}, T x_{n}\right)\right\} \\
< & \frac{1}{2}\left[d\left(T x_{n}, x_{n}\right)+d\left(T^{2} x_{n}, T x_{n}\right)\right] .
\end{aligned}
$$

Hence, we find that

$$
d\left(T x_{n}, T^{2} x_{n}\right)<d\left(T x_{n}, x_{n}\right)
$$

for each $n \in \mathbb{N}$ and

$$
\lim _{n \rightarrow \infty} d\left(z, T x_{n}\right)=d(z, w)=\lim _{n \rightarrow \infty} d\left(T x_{n}, x_{n}\right)=\theta=0 .
$$


Thus, we get $z=w$. In other words, $\left\{x_{n}\right\}$ and $\left\{T x_{n}\right\}$ converge to the same point. Due to the triangular inequality and (9), we obtain that

$$
\begin{aligned}
\lim _{n \rightarrow \infty} d\left(z, T^{2} x_{n}\right) & \leq \lim _{n \rightarrow \infty}\left[d\left(z, T x_{n}\right)+d\left(T x_{n}, T^{2} x_{n}\right)\right] \\
& \leq \lim _{n \rightarrow \infty}\left[d\left(z, T x_{n}\right)+d\left(x_{n}, T x_{n}\right)\right]=2 d(z, z)=0 .
\end{aligned}
$$

Hence, $\left\{T^{2} x_{n}\right\}$ too converges to $z$.

Assume that

$$
d\left(x_{n}, z\right) \leq \frac{1}{2} d\left(x_{n}, T x_{n}\right), \quad \text { and } \quad d\left(T x_{n}, z\right) \leq \frac{1}{2} d\left(T x_{n}, T^{2} x_{n}\right) .
$$

We use (9), (12) and the triangular inequality, we find that

$$
\begin{aligned}
d\left(x_{n}, T x_{n}\right) & \leq d\left(x_{n}, z\right)+d\left(T x_{n}, z\right) \leq \frac{1}{2} d\left(x_{n}, T x_{n}\right)+\frac{1}{2} d\left(T x_{n}, T^{2} x_{n}\right) \\
& <\frac{1}{2} d\left(x_{n}, T x_{n}\right)+\frac{1}{2} d\left(x_{n}, T x_{n}\right)=d\left(x_{n}, T x_{n}\right) .
\end{aligned}
$$

This is a contradiction. Thus, either

$$
d\left(x_{n}, z\right)>\frac{1}{2} d\left(x_{n}, T x_{n}\right), \quad \text { or } \quad d\left(T x_{n}, z\right)>\frac{1}{2} d\left(T x_{n}, T^{2} x_{n}\right)
$$

holds for each $n \in \mathbb{N}$. Then regarding (3), one of the below holds:

$$
\begin{aligned}
d\left(T x_{n}, T z\right)< & \frac{1}{2}\left[d\left(T x_{n}, x_{n}\right)+d(T z, z)\right]+L \min \left\{d\left(z, T x_{n}\right), d\left(x_{n}, T z\right), d\left(x_{n}, z\right)\right\}, \\
d\left(T^{2} x_{n}, T z\right)< & \frac{1}{2}\left[d\left(T^{2} x_{n}, T x_{n}\right)+d(T z, z)\right] \\
& +L \min \left\{d\left(z, T^{2} x_{n}\right), d\left(T x_{n}, T z\right), d\left(T x_{n}, z\right)\right\} .
\end{aligned}
$$

This is equivalent to stating that either

(i) there is an infinite subset $I$ of $\mathbb{N}$ so that the inequality (14) holds for all $n \in I$, or,

(ii) there is an infinite subset $J$ of $\mathbb{N}$ so that the inequality (15) holds for all $n \in J$.

We first consider the case (14). The inequality

$$
d(z, T z)=\lim _{n \in I, n \rightarrow \infty} d\left(T x_{n}, T z\right) \leq \lim _{n \in I, n \rightarrow \infty} \frac{1}{2}\left[d\left(T x_{n}, x_{n}\right)+d(T z, z)\right]=\frac{1}{2} d(z, T z),
$$

yields that

$$
d(z, T z)=0 .
$$

Thus, we conclude that $T z=z$. For the other case in (15) we get

$$
\begin{aligned}
d(z, T z) & =\lim _{n \in J, n \rightarrow \infty} d\left(T^{2} x_{n}, T z\right) \leq \lim _{n \in J, n \rightarrow \infty} \frac{1}{2}\left[d\left(T x_{n}, T^{2} x_{n}\right)+d(z, T z)\right] \\
& =\frac{1}{2}[d(z, z)+d(z, T z)]
\end{aligned}
$$


which implies that

$$
\frac{1}{2} d(z, T z)<\frac{1}{2} d(z, z)=0
$$

Thus, we reach the conclusion $T z=z$ again. This contradicts with the assumption that $T$ has no fixed point. Hence, $T$ has a fixed point.

Corollary 7 Let $T$ be a self mapping on a compact metric space $(X, d)$. Assume that

$$
\begin{aligned}
& \frac{1}{2} d(x, T x)<d(x, y) \\
& \quad \Rightarrow \quad d(T x, T y)<\frac{1}{2}[d(T x, x)+d(T y, y)]+L \min \{d(x, T x), d(y, T y), d(x, y)\}
\end{aligned}
$$

for all $x, y \in X$ with $x \neq y$ and $L>0$. Then, $T$ has a unique fixed point $z \in X$, that is, $T z=z$.

Proof The proof of Theorem 6 applies, mutatis mutandis, to show the existence of a fixed point. Let $z \in X$ be a fixed point of $T$.

We shall prove $z$ is the unique fixed point of $T$. Suppose, to the contrary that, there exists $y \in X$ so that $y \neq z$ and $T y=y$. Then the inequalities $d(y, z)>0$ and $0=\frac{1}{2} d(z, T z)<d(z, y)$ are satisfied. Due to (3), we have

$$
0 \leq d(z, T y)=d(T z, T y)<\frac{1}{2}[d(T z, z)+d(T y, y)]+L \min \{d(z, T z), d(y, T y), d(z, y)\}=0
$$

which is a contradiction. Hence, $z$ is the unique fixed point of $T$.

Theorem 8 Let $T$ be a self mapping on a compact metric space $(X, d)$. Assume that

$$
\begin{aligned}
& \frac{1}{2} d(x, T x)<d(x, y) \\
& \quad \Rightarrow \quad d(T x, T y)<\frac{1}{2}[d(T x, y)+d(T y, x)]+L \min \{d(y, T x), d(x, T y), d(x, y)\}
\end{aligned}
$$

for all $x, y \in X$ with $x \neq y$ and $L>0$. Then, $T$ has a fixed point $z \in X$, that is, $T z=z$.

Proof The proof of Theorem 6 applies, mutatis mutandis, to prove Theorem 8.

Corollary 9 Let $T$ be a self mapping on a compact metric space $(X, d)$. Assume that

$$
\begin{aligned}
& \frac{1}{2} d(x, T x)<d(x, y) \\
& \quad \Rightarrow \quad d(T x, T y)<\frac{1}{2}[d(T x, y)+d(T y, x)]+L \min \{d(x, T x), d(y, T y), d(x, y)\}
\end{aligned}
$$

for all $x, y \in X$ with $x \neq y$ and $L>0$. Then, $T$ has a unique fixed point $z \in X$, that is, $T z=z$.

Proof The proof of Corollary 7 applies, mutatis mutandis, to prove Corollary 9. 
Theorem 10 Let $T$ be a self mapping on a compact metric space $(X, d)$. Assume that

$$
\begin{aligned}
\frac{1}{2} d(x, T x)<d(x, y) \Rightarrow d(T x, T y)< & \frac{1}{3}[d(x, y)+d(T x, x)+d(T y, y)] \\
& +L \min \{d(y, T x), d(x, T y), d(x, y)\},
\end{aligned}
$$

for all $x, y \in X$ with $x \neq y$ and $L>0$. Then, $T$ has a fixed point $z \in X$, that is, $T z=z$.

Proof As in the proof of Theorem 6, we set $\theta=\inf \{d(x, T x): x \in X\}$ and choose a sequence $\left\{x_{n}\right\}$ in $X$ such that $\lim _{n \rightarrow \infty} d\left(x_{n}, T x_{n}\right)=\theta$. Since $X$ is compact, without loss of generality, we assume that $\left\{x_{n}\right\}$ and $\left\{T x_{n}\right\}$ converge to the points $z$ and $w$ in $X$, respectively.

We aim to show that $\theta$ is equal to zero. Let assume the contrary. Recall that

$$
\lim _{n \rightarrow \infty} d\left(x_{n}, w\right)=d(z, w)=\lim _{n \rightarrow \infty} d\left(x_{n}, T x_{n}\right)=\theta .
$$

It is possible to choose $k \in \mathbb{N}$ in such a way that

$$
\frac{2}{3} \theta<d\left(x_{n}, w\right) \quad \text { and } \quad d\left(x_{n}, T x_{n}\right)<\frac{4}{3} \theta
$$

for each $n \geq k$. Consequently, we see that $\frac{1}{2} d\left(x_{n}, T x_{n}\right)<d\left(x_{n}, w\right)$ for each $n \geq k$. By (21), we derive that

$$
\begin{aligned}
d\left(T x_{n}, T w\right)< & \frac{1}{3}\left[d\left(x_{n}, w\right)+d\left(T x_{n}, x_{n}\right)+d(T w, w)\right] \\
& +L \min \left\{d\left(w, T x_{n}\right), d\left(x_{n}, T w\right), d\left(x_{n}, w\right)\right\}
\end{aligned}
$$

for each $n \geq k$. Then it follows that

$$
d(w, T w)=\lim _{n \rightarrow \infty} d\left(T x_{n}, T w\right) \leq \lim _{n \rightarrow \infty}\left(\begin{array}{l}
\frac{1}{3}\left[d\left(x_{n}, w\right)+d\left(T x_{n}, x_{n}\right)+d(T w, w)\right] \\
+L \min \left\{d\left(w, T x_{n}\right), d\left(x_{n}, T w\right), d\left(x_{n}, w\right)\right\}
\end{array}\right)
$$

which implies that

$$
d(w, T w)=\lim _{n \rightarrow \infty} d\left(T x_{n}, T w\right) \leq \frac{1}{3}[d(z, w)+d(w, z)+d(T w, w)] .
$$

Hence, we find that $d(w, T w)<d(z, w)=\theta$. As a result, we conclude that $d(w, T w)=\theta$ when we take the definition of $\theta$ into account. Since we always have the inequality $\frac{1}{2} d(w, T w)<$ $d(w, T w)$, we obtain

$$
\begin{aligned}
d\left(T w, T^{2} w\right)< & \frac{1}{3}\left[d(w, T w)+d(T w, w)+d\left(T^{2} w, T w\right)\right] \\
& +L \min \left\{d(T w, T w), d\left(w, T^{2} w\right), d(w, T w)\right\}
\end{aligned}
$$

by applying (21). But this is equivalent to stating that $d\left(T w, T^{2} w\right)<d(T w, w)=\theta$. This contradicts with the definition of $\theta$. So, we find $\theta=0$. 
We are ready to show that $T$ has a fixed point. We shall use the method of Reductio ad absurdum again. Suppose that $T$ has no fixed point. Since the inequality $0<\frac{1}{2} d\left(T x_{n}, x_{n}\right)<$ $d\left(T x_{n}, x_{n}\right)$ is true for each $n$, the expression

$$
\begin{aligned}
d\left(T x_{n}, T^{2} x_{n}\right)< & \frac{1}{3}\left[d\left(x_{n}, T x_{n}\right)+d\left(T x_{n}, x_{n}\right)+d\left(T^{2} x_{n}, T x_{n}\right)\right] \\
& +L \min \left\{d\left(T x_{n}, T x_{n}\right), d\left(x_{n}, T^{2} x_{n}\right), d\left(x_{n}, T x_{n}\right)\right\}
\end{aligned}
$$

holds for every $n \in \mathbb{N}$. In other words, we see that the inequality

$$
d\left(T x_{n}, T^{2} x_{n}\right)<d\left(T x_{n}, x_{n}\right)
$$

is satisfied for each $n \in \mathbb{N}$. Therefore, we infer that

$$
\lim _{n \rightarrow \infty} d\left(z, T x_{n}\right)=d(z, w)=\lim _{n \rightarrow \infty} d\left(T x_{n}, x_{n}\right)=\theta=0 .
$$

So, we also find $z=w$. Thus, the sequences $\left\{x_{n}\right\}$ and $\left\{T x_{n}\right\}$ converge to the same point. By the triangular inequality, together with the inequality (27), we derive

$$
\begin{aligned}
\lim _{n \rightarrow \infty} d\left(z, T^{2} x_{n}\right) & \leq \lim _{n \rightarrow \infty}\left[d\left(z, T x_{n}\right)+d\left(T x_{n}, T^{2} x_{n}\right)\right] \\
& \leq \lim _{n \rightarrow \infty}\left[d\left(z, T x_{n}\right)+d\left(x_{n}, T x_{n}\right)\right]=2 d(z, z)=0 .
\end{aligned}
$$

Hence, $\left\{T^{2} x_{n}\right\}$ also converges to $z$. Assume that

$$
d\left(x_{n}, z\right) \leq \frac{1}{2} d\left(x_{n}, T x_{n}\right), \quad \text { and } \quad d\left(T x_{n}, z\right) \leq \frac{1}{2} d\left(T x_{n}, T^{2} x_{n}\right) .
$$

Regarding (27), (30) and the triangular inequality, we find

$$
\begin{aligned}
d\left(x_{n}, T x_{n}\right) & \leq d\left(x_{n}, z\right)+d\left(T x_{n}, z\right) \leq \frac{1}{2} d\left(x_{n}, T x_{n}\right)+\frac{1}{2} d\left(T x_{n}, T^{2} x_{n}\right) \\
& <\frac{1}{2} d\left(x_{n}, T x_{n}\right)+\frac{1}{2} d\left(x_{n}, T x_{n}\right)=d\left(x_{n}, T x_{n}\right) .
\end{aligned}
$$

This is a contradiction. Thus, we have either

$$
d\left(x_{n}, z\right)>\frac{1}{2} d\left(x_{n}, T x_{n}\right), \quad \text { or } \quad d\left(T x_{n}, z\right)>\frac{1}{2} d\left(T x_{n}, T^{2} x_{n}\right)
$$

for each $n \in \mathbb{N}$. By (21), we conclude that one of the inequalities below

$$
\begin{aligned}
d\left(T x_{n}, T z\right)< & \frac{1}{3}\left[d\left(x_{n}, z\right)+d\left(x_{n}, T x_{n}\right)+d(z, T z)\right] \\
& +L \min \left\{d\left(z, T x_{n}\right), d\left(x_{n}, T z\right), d\left(x_{n}, z\right)\right\}, \\
d\left(T^{2} x_{n}, T z\right)< & \frac{1}{3}\left[d\left(T x_{n}, z\right)+d\left(T^{2} x_{n}, T x_{n}\right)+d(T z, z)\right] \\
& +L \min \left\{d\left(z, T^{2} x_{n}\right), d\left(T x_{n}, T z\right), d\left(T x_{n}, z\right)\right\}
\end{aligned}
$$

is satisfied. This is equivalent to phrasing that either 
(a) there is an infinite subset $I$ of $\mathbb{N}$ so that

$$
\begin{aligned}
d\left(T x_{n}, T z\right)< & \frac{1}{3}\left[d\left(x_{n}, z\right)+d\left(x_{n}, T x_{n}\right)+d(z, T z)\right] \\
& +L \min \left\{d\left(z, T x_{n}\right), d\left(x_{n}, T z\right), d\left(x_{n}, z\right)\right\}, \quad \text { for all } n \in I \text { or, }
\end{aligned}
$$

(b) there is an infinite subset $J$ of $\mathbb{N}$ so that

$$
\begin{aligned}
d\left(T^{2} x_{n}, T z\right)< & \frac{1}{3}\left[d\left(T x_{n}, z\right)+d\left(T^{2} x_{n}, T x_{n}\right)+d(T z, z)\right] \\
& +L \min \left\{d\left(z, T^{2} x_{n}\right), d\left(T x_{n}, T z\right), d\left(T x_{n}, z\right)\right\},
\end{aligned}
$$

for all $n \in J$ holds.

Considering the case (32), we find

$$
\begin{aligned}
d(z, T z)= & \lim _{n \in I, n \rightarrow \infty} d\left(T x_{n}, T z\right)<\lim _{n \in I, n \rightarrow \infty} \frac{1}{3}\left[d\left(x_{n}, z\right)+d\left(x_{n}, T x_{n}\right)+d(z, T z)\right] \\
& +L \min \left\{d\left(z, T x_{n}\right), d\left(x_{n}, T z\right), d\left(x_{n}, z\right)\right\} \\
= & \frac{1}{3}[2 d(z, z)+d(z, T z)],
\end{aligned}
$$

which yields that

$$
\frac{2}{3} d(z, T z) \leq \frac{2}{3} d(z, z)=0 .
$$

Thus, we conclude that $T z=z$. For the other case (33), we obtain

$$
\begin{aligned}
d(z, T z)= & \lim _{n \in J, n \rightarrow \infty} d\left(T^{2} x_{n}, T z\right) \leq \lim _{n \in J, n \rightarrow \infty} \frac{1}{3}\left[d\left(T x_{n}, z\right)+d\left(T x_{n}, T^{2} x_{n}\right)+d(z, T z)\right] \\
& +L \min \left\{d\left(z, T^{2} x_{n}\right), d\left(T x_{n}, T z\right), d\left(T x_{n}, z\right)\right\} \\
= & \frac{1}{3}[2 d(z, z)+d(z, T z)]
\end{aligned}
$$

which implies

$$
\frac{2}{3} d(z, T z)<\frac{2}{3} d(z, z)=0 .
$$

Thus, we reach the same conclusion, that is, $T z=z$. This contradicts with assumption that $T$ has no fixed point. Hence, $T$ has a fixed point, say $z \in X$.

Corollary 11 Let $T$ be a self mapping on a compact metric space $(X, d)$. Assume that

$$
\begin{aligned}
\frac{1}{2} d(x, T x)<d(x, y) \Rightarrow d(T x, T y)< & \frac{1}{3}[d(x, y)+d(T x, x)+d(T y, y)] \\
& +L \min \{d(y, T x), d(x, T y), d(x, y)\},
\end{aligned}
$$

for all $x, y \in X$ with $x \neq y$ and $L>0$. Then, $T$ has a unique fixed point $z \in X$, that is, $T z=z$. 
Proof The proof of Corollary 13 follows, mutatis mutandis, from the proofs of Corollary 7 , Corollary 9 and Corollary 11. Therefore $T$ has a fixed point, say $z \in X$.

We need to prove $z$ is the unique fixed point of $T$. Suppose, to the contrary that, there exists $y \in X$ such that $y \neq z$ and $T y=y$. Then, we have $d(y, z)>0$ and $0=\frac{1}{2} d(z, T z)<d(z, y)$. By (21), we see that

$$
\begin{aligned}
d(z, T y) & =d(T z, T y)<\frac{1}{3}[d(z, y)+d(T z, z)+d(T y, y)]+L \min \{d(y, T z), d(z, T y), d(z, y)\} \\
& =\frac{1}{3}[d(z, y)+d(T y, y)] \\
& \leq \frac{1}{3}[d(z, y)+d(T y, z)+d(z, y)]
\end{aligned}
$$

which in turn implies that $d(z, T y)<d(z, y)$. So $y$ is not a fixed point of $T$. Hence, $z$ is the unique.

Combining Theorem 6, Theorem 8 and Theorem 10 yields the following:

Theorem 12 Let $T$ be a self mapping on a compact metric space $(X, d)$. Assume that

$$
\begin{aligned}
\frac{1}{2} d(x, T x)<d(x, y) \Rightarrow d(T x, T y)< & \frac{1}{3}[d(x, y)+d(T x, y)+d(T y, x)] \\
& +L \min \{d(y, T x), d(x, T y), d(x, y)\}
\end{aligned}
$$

for all $x, y \in X$. Then, $T$ has a fixed point $z \in X$, that is, $T z=z$.

Combining Corollary 7, Corollary 9 and Corollary 11 yields the following:

Corollary 13 Let $T$ be a self mapping on a compact metric space $(X, d)$. Assume that

$$
\begin{aligned}
\frac{1}{2} d(x, T x)<d(x, y) \Rightarrow d(T x, T y)< & \frac{1}{3}[d(x, y)+d(T x, y)+d(T y, x)] \\
& +L \min \{d(y, T x), d(x, T y), d(x, y)\}
\end{aligned}
$$

for all $x, y \in X$. Then, $T$ has a unique fixed point $z \in X$, that is, $T z=z$.

The result below is a corollary of Theorem 6-Theorem 12:

Theorem 14 Let $T$ be a self mapping on a compact metric space $(X, d)$. Assume that

$$
\begin{aligned}
\frac{1}{2} d(x, T x)<d(x, y) & \\
\Rightarrow \quad d(T x, T y)< & \frac{1}{5}[d(x, y)+d(T x, x)+d(T y, y)+d(T x, y)+d(T y, x)] \\
& +L \min \{d(y, T x), d(x, T y), d(x, y)\}
\end{aligned}
$$

for all $x, y \in X$. Then, $T$ has a fixed point $z \in X$, that is, $T z=z$.

Proof The proof of Theorem 12 follows from the proofs of the previous theorems verbatim. 
Corollary 15 Let $T$ be a self mapping on a compact metric space $(X, d)$. Assume that

$$
\begin{aligned}
\frac{1}{2} d(x, T x)<d(x, y) & \\
\Rightarrow \quad d(T x, T y)< & \frac{1}{5}[d(x, y)+d(T x, x)+d(T y, y)+d(T x, y)+d(T y, x)] \\
& +L \min \{d(x, T x), d(y, T y), d(x, y)\}
\end{aligned}
$$

for all $x, y \in X$. Then, $T$ has a unique fixed point $z \in X$, that is, $T z=z$.

Proof The proof of Corollary 13 follows from the proofs of the previous theorems verbatim.

Example 16 ( $c f$. [17]) Let $X=\mathbb{Z}$ and $d$ be the discrete metric

$$
d(x, y)= \begin{cases}1 & \text { if } x \neq y \\ 0 & \text { if } x=y\end{cases}
$$

Each self-mapping $T$ on $X$ satisfying (18) has a unique fixed point. It is clear that $(X, d)$ is complete, but it is not a compact metric space. Let $T$ be a self-mapping on $X$. If $T$ has a fixed point, it is sufficient to prove that it is unique.

To show that $z \in X$ is the unique fixed point of $T$, we take $y \in X$ where $y \neq z$. Thus the inequalities $d(y, z)=1>0$ and $0=\frac{1}{2} d(z, T z)<d(z, y)$ are satisfied. Due to (18), we have

$$
\begin{aligned}
d(z, T y) & =d(T z, T y)<\frac{1}{2}[d(T z, z)+d(T y, y)]+L \min \{d(z, T z), d(y, T y), d(z, y)\} \\
& =\frac{1}{2} d(T y, y) \leq \frac{1}{2}[d(T y, z)+d(z, y)]
\end{aligned}
$$

which implies that $d(z, T y)<d(z, y)$. So $y$ is not a fixed point of $T$. Hence, $z$ is the unique fixed point of $T$. Suppose $T$ has no fixed point. Then, we have

$$
\frac{1}{2} d(x, T x) \leq \frac{1}{2}<d(x, y)=1, \quad \text { for all } x, y \in X \text {, with } x \neq y .
$$

Due to (18), the inequality $d(T x, T y)<\frac{1}{2}[d(T x, x)+d(T y, y)]+L \min \{d(x, T x), d(y, T y)$, $d(x, y)\}=1$ holds. In other words, we get $d(T x, T y)=0$. Thus the image of $T$ on the domain $X$ consists of only one point which is clearly a unique fixed point. This is a contradiction.

Remark 17 Example 16 can be modified for Theorem 8-Theorem 10 just by replacing the condition (3) with the relevant one. It is clear that proofs are obtained by apply the necessary manipulations in Example 16.

The following theorem is a generalization of [17, Theorem 5]. 
Theorem 18 Let $T$ be a self mapping on a metric space $(X, d)$. Suppose that there exist $k \in[0,1)$ and a $T$-invariant complete subset $K$ of $X$ such that

$$
\begin{aligned}
& d(T x, T y) \leq k d(x, y) \quad \text { and } \\
& d(T z, T w)<\frac{1}{2}[d(T z, z)+d(T w, w)]+L \min \{d(w, T w), d(z, T z), d(z, w)\}
\end{aligned}
$$

for all $x, y \in K$ with $x \neq y$, and $z, w \in X$ with $z \neq w$ and $L>0$. Then, $T$ has a unique fixed point $u \in X$, that is, $T u=u$.

Proof Due to Banach [8], there exists a unique fixed point $u \in K$. Consider

$$
\begin{aligned}
d(T z, u) & =d(T z, T u)<\frac{1}{2}[d(T z, z)+d(T u, u)] \\
& \leq \frac{1}{2}[d(T z, u)+d(u, z)]+L \min \{d(u, T u), d(z, T z), d(z, u)\},
\end{aligned}
$$

for all $z \in(X \backslash K)$ which implies that

$$
d(T z, T u)<d(u, z) .
$$

In other words, for all $z \in(X \backslash K)$ is not a fixed point of $T$. Hence, $u$ is the unique fixed point of $T$ on $X$.

Remark 19 Theorem 18 holds also if we replace one of the conditions below instead of the condition (41):

$$
\begin{aligned}
& d(T x, T y) \leq k d(x, y) \quad \text { and } \\
& d(T z, T w)< \frac{1}{2}[d(T z, w)+d(T w, z)]+L \min \{d(w, T w), d(z, T z), d(z, w)\}, \\
& d(T x, T y) \leq k d(x, y) \quad \text { and } \\
& d(T z, T w)<\frac{1}{3}[d(z, w)+d(T z, z)+d(T w, w)]+L \min \{d(w, T w), d(z, T z), d(z, w)\}, \\
& d(T x, T y) \leq k d(x, y) \quad \text { and } \\
& d(T z, T w)<\frac{1}{3}[d(z, w)+d(T z, w)+d(T w, z)]+L \min \{d(w, T w), d(z, T z), d(z, w)\}, \\
& d(T x, T y) \leq k d(x, y) \quad \text { and } \\
& d(T z, T w)<\frac{1}{5}[d(z, w)+d(T z, z)+d(T w, w)+d(T z, w)+d(T w, z)] \\
&+L \min \{d(w, T w), d(z, T z), d(z, w)\} .
\end{aligned}
$$

The author declares that they have no competing interests.

\section{Acknowledgements}

The author express his gratitude to the referees for constructive and useful remarks and suggestions. 


\section{References}

1. Border, KC: Fixed Point Theorems with Applications to Economics and Game Theory. Cambridge University Press, New York (1985)

2. Ok, EA: Real Analysis with Economic Applications. Princeton University Press, Princeton (2007)

3. Karapınar, E: Generalizations of Caristi Kirk's theorem on partial metric spaces. Fixed Point Theory Appl. 2011, Article ID 4 (2011)

4. Karapınar, E: A note on common fixed point theorems in partial metric spaces. Miskolc Math. Notes 12(2), 185-191 (2011)

5. Mathews, GS: Partial metric topology. Reseach Report 212, Dept. of Computer Science University of Warwick (1992)

6. Romaguera, S, Valero, O: A quantitative computational model for complete partialmetric spaces via formal balls. Math. Struct. Comput. Sci. 19(3), 541-563 (2009)

7. Schellekens, MP: The correspondence between partial metrics and semivaluations. Theor. Comput. Sci. 315, 135-149 (2004)

8. Banach, S: Sur les operations dans les ensembles abstraits et leur application aux equations itegrales. Fundam. Math. 3, 133-181 (1922)

9. Kannan, R: Some results on fixed points. Bull. Calcutta Math. Soc. 60, 71-76 (1968)

10. Reich, S: Kannan's fixed point theorem. Boll. Unione Mat. Ital. 4(4), 1-11 (1971)

11. Hardy, GE, Rogers, TD: A generalization of a fixed point theorem of Reich. Can. Math. Bull. 16, 201-206 (1973)

12. Ćirić, LB: A generalization of Banach principle. Proc. Am. Math. Soc. 45, 727-730 (1974)

13. Ćirić, LB: Coincidence and fixed points for maps on topological spaces. Topol. Appl. 154, 3100-3106 (2007)

14. Ćirić, L: Some new results for Banach contractions and Edelstein contractive mappings on fuzzy metric spaces. Chaos Solitons Fractals 42, 146-154 (2009)

15. Zamfirescu, T: Fix point theorems in metric spaces. Arch. Math. 23, 292-298 (1972)

16. Arshad, M, Azam, A, Vetro, P: Some common fixed point results in cone metric spaces. Fixed Point Theory Appl. 2009 Article ID 493965 (2009)

17. Suzuki, K: A new type of fixed point theorem in metric spaces. Nonlinear Anal., Theory Methods Appl. 71(11), 5313-5317 (2009)

18. Suzuki, K: A generalized Banach contraction principle that characterizes metric completeness. Proc. Am. Math. Soc. $136,1861-1869(2008)$

19. Altun, I, Erduran, A: A Suzuki type fixed-point theorem. Int. J. Math. Math. Sci. 2011, Article ID 736063 (2011)

20. Doric, D, Lazovic, R: Some Suzuki type fixed point theorems for generalized multivalued mappings and applications. Fixed Point Theory Appl. 2011, Article ID 40 (2011)

21. Karapınar, E: Remarks on Suzuki (C)-condition. In: Dynamical Systems and Methods, pp. 227-243 (2012). doi:10.1007/978-1-4614-0454-5_12

22. Karapınar, E, Tas, K: Generalized (C)-conditions and related fixed point theorems. Comput. Math. Appl. 61(11), 3370-3380 (2011)

23. Singh, SL, Pathak, HK, Mishra, SN: On a Suzuki type general fixed point theorem with applications. Fixed Point Theory Appl. 2010, Article ID 234717 (2010)

24. Edelstein, M: On fixed and periodic points under contractive mappings. J. Lond. Math. Soc. 37, 74-79 (1962)

25. Berinde, V: Approximation fixed points of weak contractions using the Picard iteration. Nonlinear Anal. Forum 9(1), 43-53 (2004)

doi:10.1186/1687-1812-2012-107

Cite this article as: Karapınar: Edelstein type fixed point theorems. Fixed Point Theory and Applications 2012 2012:107.

\section{Submit your manuscript to a SpringerOpen ${ }^{\circ}$ journal and benefit from:}

- Convenient online submission

Rigorous peer review

- Immediate publication on acceptance

Open access: articles freely available online

- High visibility within the field

- Retaining the copyright to your article 